\title{
Memoria y redención: el lugar de los vencidos
}

Reyes Mate, Medianoche en la historia: Comentarios a las tesis de Walter Benjamin "Sobre el concepto de historia», Trotta, Madrid, 2006.

- n la historia encontramos "vencedores" y "vencidos", "grandeza" y "miseria", "progreso" y "barbarie". El pensamiento de Walter Benjamin parte de esa constatación. Pero su interés en la historia no lleva el sello de una ingenua objetividad. Tampoco entiende la historia como la acumulación lineal de hechos que cobran sentido desde el presente, desde un presente atravesado por los intereses de los vencedores. Denuncia toda actitud triunfal, encantada por el "progre- 
so", ya que sabe ver la barbarie sobre la que se ha construido el susodicho progreso. Por eso declara que "no hay un solo documento de cultura que no lo sea a la vez de barbarie. Y si el documento no está libre de barbarie, tampoco lo está el proceso de transmisión de unas manos a otras. Por eso el materialista histórico toma sus distancias en la medida de lo posible. Considera tarea suya cepillar la historia a contrapelo".

Benjamin piensa desde una deslumbrante obsesión: que los cadáveres de los triturados por la historia no deben asumirse como unos entes más de la naturaleza (ríos, montañas, etc.). El filósofo judío se resiste a leer los cadáveres de los vencidos como losas de concreto sobre las que levantamos nuestro progreso. Va más allá de Horkheimer cuando nos habla de la redención de los vencidos. Esta idea mesiánica se articula con otra poderosa categoría judía, la memoria.

Escribe al respecto: "Es seguro que el tiempo no fue experimentado ni como homogéneo ni como vacío por los adivinos que escrutaban lo que esconde en su seno. Quien tenga esto presente, comprenderá quizás cómo se ha experimentado el tiempo pasado en la memoria: del mismo modo. Es sabido que a los judíos les estaba prohibido indagar sobre el futuro. La Torá y la plegaria les instruyen, en cambio, en la memoria. Ella les desencantaba el futuro al que sucumbían quienes buscaban información en los adivinos. Pero gracias a ello el futuro no se convirtió para los judíos en un tiempo homogéneo y vacío. Pues en él cada segundo era la pequeña puerta por la cual podía entrar el Mesías".

Benjamin, pues, bebe en la fuente del materialismo histórico y en la de la tradición mesiánica judía. Pero frente al marxismo no adopta una actitud ingenua. Al contrario, le echa en cara la adopción acrítica de la ideología progresista del positivismo. Por eso afirma que el auténtico materialista histórico debe asumir la penosa tarea de escribir la historia a contracorriente. Penosa en dos sentidos: porque hay que "cepillar la historia a contra pelo" y porque el historiador debe convertirse en trapero, es decir, tiene que escarbar en los desechos que no cuentan para el tiempo "lineal, homogéneo y vacío" del historicista.

Para este filósofo el pasado no se debe estudiar para encuadrar mejor el presente, como si los masacrados, torturados y desaparecidos fuesen los ladrillos demandados por el progreso presente. Una lectura así legitima siempre el orden de los vencedores. Piensa el pasado en destellos. Por eso recurre a la memoria. Declara Reyes Mate: "Lo propio, por tanto, de la mirada de la memoria es, en primer lugar, la atención al pasado ausente del presente $y$, en segundo, considerar esos fracasos o víctimas no como datos naturales que están ahí como están los ríos o las montañas, sino 
como una injusticia, como una frustración violenta de su proyecto de vida. La mirada del historiador benjaminiano se emparenta con la del alegorista barroco que no considera las ruinas y cadáveres como naturaleza muerta, sino como vida frustrada, una pregunta que espera respuesta de quien lo contemple. Esa atención a lo fracasado, a lo desechado por la lógica de la historia es profundamente inquietante y subversiva, tanto desde el punto de vista epistémico como político, porque cuestiona la autoridad de lo fáctico".

La interpretación que Reyes Mate hace de Benjamin sobresale en cuanto que plantea la posibilidad de una nueva epistemología y de una nueva política a partir del pensamiento del filósofo judeoalemán. Los vencidos de la historia y los excluidos de la globalización constituyen el lugar de verdad en el que se constata el desastre humano que genera el progreso. Por otro lado, del lado político, la injusticia social no es un "estado de excepción" respecto del progreso, es su regla. Escribe Benjamin: "La tradición de los oprimidos nos enseña que el 'estado de excepción' en el que vivimos es la regla". El autor escribe esto al ver la situación de los judíos en la Alemania de Hitler. Critica a aquellos que se sorprenden ante las políticas represivas, de exterminio y de expansión de los nazis. Como buen filósofo, tiene claro que no está frente a un estado de excepción, sino frente a una realidad que es la regla de toda ideología progresista, una realidad en la que la historia la hacen los vencedores, en la que el progreso exige víctimas.

Contextualizando las ideas benjaminianas, la pobreza y la marginación social no constituyen un momento de excepción, es decir, superable en alguna etapa subsiguiente. Al contrario: la situación de hambruna y de miseria de gran parte de la población mundial constituye la regla indispensable para poder sostener el éxito, la buena vida y el despilfarro del primer mundo.

Benjamín, pues, es un pensador que nos invita a pensar desde los desechos de la historia, desde esos "no-lugares" que son irrelevantes para la historiografía de oficio. Es un pensador que con sus categorías de redención y memoria plantea el reto de leer nuestros diversos pasados no para legitimar el presente, sino para llevar luz a los olvidados por la historia, para alumbrar el presente desde la memoria de las víctimas del pasado.

En pocas palabras, quiere un ángel en la historia, el ángel de la historia: "Hay un cuadro de Klee que se llama Angelus Novus. Representa a un ángel que parece estar a punto de alejarse de algo a lo que está clavada su mirada. Sus ojos están desencajados, la boca abierta, las alas desplegadas. El ángel de la historia tiene que parecérsele. Tiene el rostro vuelto hacia el pasado. Lo que a nosotros se presenta como 
una cadena de acontecimientos, él lo ve como una catástrofe única que acumula sin cesar ruinas sobre ruinas, arrojándolas a sus pies. Bien quisiera él detenerse, despertar a los muertos y recomponer los fragmentos. Pero desde el paraíso sopla un viento huracanado que se arremolina en sus alas, tan fuerte que el ángel no puede plegarlas. El huracán le empuja irresistiblemente hacia el futuro, al que da la espalda, mientras el cúmulo de ruinas crece hasta el cielo. Eso que nosotros Ilamamos progreso es ese huracán".

Con claridad magistral Reyes Mate nos introduce en la verdad y radicalidad del pensamiento benjaminiano. Una radicalidad que nos obsequia una perspectiva crítica para enjuiciar un mundo globalizado en el que la injusticia social es la regla, no la excepción. Desde Benjamin se puede repensar la praxis política, el compromiso ético y la búsqueda de la verdad. Su reflexión arroja luz en esos "no-lugares" invisibilizados por la verdad de los vencedores de la historia.

Julián González Torres Departamento de Filosofía UCA, San Salvador 